\title{
Aos herdeiros de um presidente breve
}

Laura Greenhalgh

E

A NOSSA luta para restaurar no país a democracia é realmente uma luta titânica. É que não nos bastará a democracia política. Esta, nós haveremos de restaurá-la com a convocação de uma Assembleia Constituinte. Não nos bastará a realização de uma democracia econômica mais justa, mais humana e mais equitativa de distribuição de riqueza. $\mathrm{O}$ problema maior que temos pela frente é a democracia social. A defasagem em nosso país entre as criaturas humanas marginalizadas na vida social e aquela minoria que se locupleta com os privilégios de uma ordem social injusta é realmente uma das mais pungentes, das mais duras e das mais penosas.

Essas palavras foram recortadas de um discurso de improviso feito por Tancredo Neves, então presidente eleito do Brasil, por ocasião do banquete que lhe foi oferecido pelo ex-primeiro-ministro de Portugal Mário Soares, no Palácio Nacional de Sintra, em janeiro de 1985. Discurso arquitetado sob as emoções do momento, para uma plateia de cem pessoas, em que o homenageado insistiu nos laços fraternais que ligavam os dois países e no retorno de ambos à democracia. Porém, por trás dos brindes e vivas, aquela fala ao sabor da hora de certo revelava o que silenciosamente se passava na cabeça de Tancredo, o presidente breve. Sua preocupação com um país que haveria de encerrar o longo capítulo ditatorial e teria plena condição de retomar seu crescimento econômico. O problema, contudo, seria fazê-lo mais justo e próspero para sua gente. Eis a "luta titânica" que teria pela frente, admitiu publicamente o orador.
O livro Diário de bordo - A viagem presidencial de Tancredo, escrito e organizado pelo embaixador e ex-ministro Rubens Ricupero, presta-se a catapultar revelações. Como esta, a de que o presidente eleito para substituir os militares no poder inquietava-se mais com a desigualdade brasileira do que com as chances de êxito da nossa ainda incerta recomposição democrática. São revelações importantes, as do livro. E não competem entre si, como se pretendessem a dianteira da história, mas juntam-se para formar o mosaico que explica um período singularíssimo da vida nacional.

Tancredo Almeida Neves fora eleito por via indireta em 15 de janeiro de 1985, como quis e estipulou o regime militar iniciado com o golpe de 1964. O governo de João Baptista Figueiredo, o último general-presidente, começava a ser engavetado para que tivesse início um novo ciclo político no país, co- $^{-}$ mandado agora por um presidente civil. Militares da linha dura não viam com bons olhos a distensão "lenta, gradual e segura" propugnada, desde antes, pelo general Geisel. Ouviam-se declarações impertinentes de militares da chamada "linha dura". E havia até rumores de golpe. Fundadas ou infundadas as ameaças, seria preciso garantir um mínimo de estabilidade política ao país, evitando a cilada das provocações irresponsáveis naqueles dois meses que separavam a vitória de Tancredo da sua posse. Como fazer? A ideia que se firmou naquele momento foi tirar Tancredo de cena, sem no entanto anular-lhe a presença.

Uma viagem presidencial parecia ser 
o melhor arranjo político para cruzar aquela fase curta, mas delicada, de uma certa hibernação institucional. E assim foi montado o périplo internacional do presidente, entre janeiro e fevereiro de 1985, alcançando países amigos na Europa e na América Latina, passando estrategicamente pelos Estados Unidos, a potência que deu apoio aos militares brasileiros durante bom tempo, e indo também buscar as bênçãos do papa, logo na etapa inicial, o que seria efetivo aos olhos do povo de um país predominantemente católico. Como o autor dá a entender logo na introdução do livro, montou-se naquele momento uma assessoria diplomática para o presidente eleito, liderada pelo embaixador Paulo de Tarso Flecha de Lima, da qual fez parte o próprio Ricupero, como conselheiro em política internacional. Na época chefe do Departamento das Américas, o setor do Itamaraty que se ocupa das relações bilaterais com os países das três Américas, Ricupero conta ter recebido o convite para integrar o grupo (que parece ter começado a operar já na campanha presidencial) e ter ido consultar seus superiores - o então secretário-geral do Itamaraty, embaixador João Clemente Baena Soares, e o ministro das Relações Exteriores, embaixador Ramiro Saraiva Guerreiro. Seria conveniente afastar-se de suas funções na chancelaria para se engajar num projeto eminentemente político? Foi liberado para aceitar o convite em caráter pessoal, "por sua conta e risco".

Há algo interessante a destacar na passagem: vê-se a prudência com que certos quadros do Itamaraty se movimentavam diante de uma nova conjuntura, mesmo não havendo maiores pontos de atrito da política externa ditada por Figueiredo com as diretrizes prenunciadas para os tempos vindouros. Assim, esse "por sua conta e risco" tanto seria portador de um aviso de cautela, como de uma sutil anuência. O grupo assessor, capitaneado pelo embaixador Paulo Tarso Fecha de Lima, diplomata experiente, com bom trânsito político e posições avançadas no campo econômico, promove como que um curso intensivo de relações internacionais para o futuro governante, tarimbado em política interna, mas carente de atualização no plano externo. Os diplomatas, afirma Ricupero, organizam o trabalho inspirados em uma manifestação de Tancredo, de novembro de 1984, quando ainda candidato: "Tenho mesmo dito que, se há um ponto na política brasileira que encontrou um consenso de todas as correntes de pensamento, esse ponto é a política externa levada a efeito pelo Itamaraty".

Esse consenso, explica Ricupero, bem pouco tem a ver com a política externa de Castello Branco, no primeiro governo militar, profundamente marcada pelas tensões da guerra fria e pelo golpe que depôs o presidente João Goulart. Mas terá a ver, especialmente, com a política externa de Geisel, executada pelo chanceler Azeredo da Silveira, em que vários passos se dão no sentido de uma diplomacia mais equilibrada e autônoma: o estabelecimento de relações com a China Popular, a ruptura com o colonialismo português, o reconhecimento do processo de independência de Angola, o Acordo de Cooperação Nuclear com a Alemanha e o Tratado de Cooperação Amazônica exemplificam tais passos. E mesmo no governo Figueiredo, não se pode esquecer da conclusão de negociações entre Brasil e Paraguai para a construção da Hidrelétrica de Itaipu. Ricupero admite: 


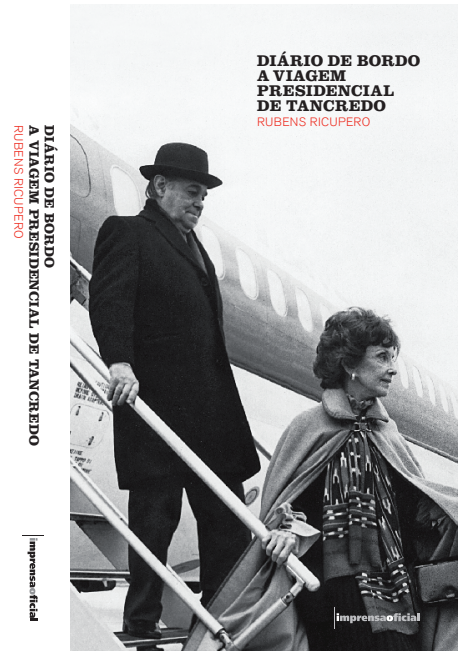

RICUPERO, Rubens. Diário de bordoA viagem presidencial de Tancredo.

São Paulo: Imprensa Oficial do Estado de São Paulo, 2010. 406p.

Exceto no caso de Cuba, não é exagero sustentar que, ao findar o regime militar, estava em grande parte realizado o programa esboçado pela Política Exterior Independente de San Tiago Dantas ou de Araújo Castro, os dois ministros que haviam levado adiante a mudança do paradigma da política externa do Brasil, iniciada pelo presidente Jânio Quadros.

Ainda na introdução do livro, o autor se preocupa em traçar coordenadas no mapa das relações internacionais da época, situando melhor o primeiro governo civil pós-regime militar. Por exemplo, a eleição de Tancredo coincide com a reeleição de Reagan nos Estados Unidos, que consolidaria a liderança mundial americana, e também com o início da ascensão de Mikhail Gorbatchev, recémeleito secretário-geral do Partido Comunista da ex-União Soviética, o que pode ser tomado como marco inicial do processo político que levou ao desmantelamento do bloco soviético e ao fim da guerra fria. Tancredo, no entanto, não viveria para ver a culminância da revolução neoconservadora, a intensificação dos processos de globalização e nem veria tombar o muro de Berlim, símbolo do fim de uma era. Mas até que ponto as forças subterrâneas dessas grandes mudanças já faziam tremer o chão em que Tancredo pisava? O olhar retrospectivo sobre esse período, que se desdobraria em episódios tão decisivos, reflete a sofisticação analítica do autor de Diário de bordo. Tem-se a dimensão quase palpável da passagem do tempo e de como os homens públicos se reinventam como atores da história.

Voltemos ao périplo presidencial. Ricupero conta que, definido o roteiro de visitas, decidiu reservar uma agenda para anotar suas impressões da viagem, como um diário de bordo mesmo, e tem-se aí a mais instigante do livro. Com absoluta sinceridade, o autor conta ter hesitado anos até resolver publicar as anotações. Porque sentiu ter trabalhado no "pedestal de um monumento que nunca chegou a ser erguido", já que Tancredo morreria pouco depois, sem tomar posse: "É um pouco essa sensação que me deixou aquela correria pelo mundo afora, a frustração de uma esperança, uma promessa sem realização, aventura terminada antes de começar. Valeria a pena por à prova a paciência do leitor com a narrativa de uma frustração?”. A opção contrária teria sido deixar os manuscritos dormirem no fundo da gaveta. Prevaleceu o bom senso.

Ao reeditar esse material, o autor descortina um período decisivo da transição democrática brasileira, mas não só. Entre comentários sem compromisso, alguns até em tom pessoal, e ricas análises de política externa, mostra como são va- 
riadas, e efetivas, as possibilidades da diplomacia presidencial, em que tudo tem peso e sentido: desde a lida com acordos e tratados internacionais à imponderável química pessoal entre governantes. Em artigo publicado na imprensa e recuperado como um dos capítulos de Diário de bordo, o ex-ministro chanceler Celso Lafer define a importância daquele giro internacional:

A viagem de Tancredo Neves [...] acabou sendo o seu momento presidencial, por força das circunstâncias que levaram à sua doença e morte. Esse breve momento teve, no entanto, um alcance importante que foi o de marcar, no plano internacional, o significado das transformações internas ocorridas em nosso país com o advento da Nova República.

Aos diplomatas envolvidos nesses deslocamentos estava reservada a missão de atender a um governante com "a expectativa de poder e não com a realidade do poder", como salienta Ricupero. Isso, por si só, gera situações pouco usuais. $\mathrm{O}$ compromisso de assessorar o presidente constantemente era acompanhado da necessidade, e também da curiosidade, de conhecê-lo melhor, de captar suas idiossincrasias, suas falas, seus silêncios, suas tiradas de humor. O estilo de Tancredo, o eleito sem farda nem patente, constituía uma novidade em si. Manifestava-se, por exemplo, na formatação da comitiva que o acompanhou na viagem: um grupo reduzido de pessoas, entre assessores e poucos familiares, viagens feitas em voos comerciais, com classe executiva apenas para o presidente e senhora, simplicidade nos gestos, discrição nas falas, austeridade nos modos. Isso criou, nos círculos da imprensa, a possibilidade imediata de comparação com as comitivas oficiais da fase final do regime militar, marcadas por excentricidades de mau gosto e protagonizadas por assessores em cascata.

E foi assim, com sua mineirice sóbria, que Tancredo chegou a Roma em 25 de janeiro de 1985, primeira parada do roteiro. É quando o autor do diário registra:

Não há sinal ainda da avidez de consumir, da vulgaridade com laivos de arrogância da fauna de ajudantes de ordem que povoavam, até passado recente, as viagens presidenciais, uns de costumes bizarros como de vestir uniformes esportivos logo após a decolagem... Mesmo o pessoal da segurança, da Polícia Militar de Minas, tem comportamento discreto, não se faz notar.

Entre os vários pontos a destacar do capítulo italiano da viagem, há a comparação reveladora que o autor faz do socialista Bettino Craxi, então chefe do governo, com o democrata-cristão que o antecedeu no posto, o veterano senador Amintore Fanfani. Ambos estiveram com Tancredo e desses momentos resulta um Craxi calculista, ortodoxo em termos econômicos, desinteressado das questões sociais em geral e descrente da América Latina. Em contrapartida, Fanfani deixa em Tancredo e no grupo a impressão dominante de sua inteligência e seu humanismo.

Outro aspecto a destacar no diário tem a ver com a audiência concedida ao presidente eleito pelo papa João Paulo II no Vaticano, que teria durado exatos 43 minutos, quando o tempo protocolar procura não exceder os 15 minutos. Esperava-se uma crítica mais dura do pontífice à disseminação da Teologia da Libertação na América Latina, Brasil incluído. Talvez parte do que foi dito pelo papa Tancredo não chegou a revelar ao 
grupo diplomático. Mas surpreendeu-o a declaração do cardeal Casaroli, então secretário de Estado no Vaticano, ao término da visita, como atesta o diário. Disse o cardeal a Tancredo:

Senhor Presidente, tenho a certeza de que o Santo Padre terá acolhido com grande alegria esse fervoroso testemunho de filial devoção do querido povo brasileiro [...]. E terá certamente comentado com Vossa Excelência que é preciso nunca esquecer que a fé profunda e a religiosidade são sempre admiráveis, mas não bastam. É preciso agir para mudar a situação, para melhorar as condições de vida do povo, não só resignar-se. É preciso realizar a reforma agrária e as demais reformas sociais aconselháveis.

O papa falando em reforma agrária? "Senti que o doutor Tancredo não esperava por esse tipo de resposta", escreve Ricupero.

Pois na fala de Casaroli manifestavamse contrastes que iriam se intensificar no pontificado de João Paulo II. O papa anticomunista, como ficaria conhecido nos anos seguintes, defensor inabalável dos dogmas católicos, conservador em temas relacionados à família e à reprodução humana, teria muito mais jogo de cintura quando se tratava de articular a defesa dos pobres e o combate às desigualdades sociais.

Na ida à França, Tancredo tem oportunidade de se encontrar com o presidente François Mitterrand, em casa desse, na cidade de Biarritz. O diário descreve o cenário da conversa: uma construção do século XVIII, não muito grande, agradável, rústica, com travões de madeira no teto... Detalhes desimportantes? Não nos parecem. Diário de bordo é feito de uma trama particular, em que o autor alinhava situações mais ou menos oficiais que acabam por revelar o caráter dos homens públicos escondido nas dobraduras do protocolo diplomático. Por exemplo, no jantar privé em Biarritz, Mitterrand sente-se à vontade para se queixar a Tancredo das críticas que lhe faziam, especialmente aqueles que não reconheciam seus esforços para abaixar a inflação na França de 6\% para 3\% ao ano. Ricupero também conta que Tancredo, de volta a Roma, escreve uma pequena carta de agradecimento a Mitterrand pela acolhida simpática. São linhas reveladoras do estilo Tancredo:

Quando descrevi o simpático ambiente de sua casa e as peças de estanho que a ornamentam, minha mulher pediu-me para fazer chegar à senhora Mitterrand, em seu nome, uma peça de artesanato de estanho produzida em minha cidade natal, São João Del Rey, que espero seja do seu agrado.

Nos encontros em Portugal, tem-se um Tancredo mais descontraído, mais seguro e até à vontade para cometer certos deslizes como orador, sendo acolhido alegremente por Mário Soares, primeiro-ministro, e Ramalho Eanes, presidente. O diário também traz anotações em torno da solenidade em que Tancredo é aceito como doutor honoris causa da Universidade de Coimbra. Fica-se sabendo, por exemplo, que seu discurso de agradecimento teve polimento final do escritor maranhense Josué Montello - o texto, na íntegra, está no livro. Na Espanha, o presidente eleito é recebido pelo casal real e também pelo primeiro-ministro socialista Felipe González, estrela política da época. Tancredo pergunta a Felipe que conselhos lhe daria para fazer um bom governo. Com idade para ser seu filho, Felipe responde com o conselho que lhe fora dado pelo primeiro-ministro sueco Olof Palme, ao 
responder exatamente à mesma pergunta: "Escolha um bom ministro da Economia e $80 \%$ dos seus problemas estarão resolvidos". O que diz muito do processo de estabilização monetária que levou ao Plano Real no Brasil.

Já a ida aos Estados Unidos mostra Tancredo exposto a um cenário mais complexo, de conversas pragmáticas e jogo calculado. Ao lidar com personalidades como o presidente Ronald Reagan, George Bush (o pai, e vice na Casa Branca) e o secretário de Estado George Schulz, entrou num campo do qual certamente não tinha todos os dados. Schulz, ninguém menos do que ele, é quem comunica a Tancredo que as emissões brasileiras em 1984 haviam superado as metas estabelecidas, que havia previsão de salto inflacionário para a casa dos $300 \%$ ao ano e que, se não fossem mantidos os termos originais do acordo com o FMI, as consequências seriam desastrosas. Shulz perguntava-se se haveria espaço de renegociação da dívida brasileira ou se o fundo deveria denunciar o acordo antes da posse do novo governo.

Ao recompor esse momento tenso da viagem, Ricupero tem campo de visão para descrever a capacidade de reação de Tancredo em terreno adverso. $\mathrm{O}$ presidente eleito diz a seus interlocutores em Washington que as preocupações do governo americano são também as dele, mas que, ao assinarem aquele acordo, nem a parte americana nem a brasileira teriam agido com "sinceridade", porque as metas estabelecidas eram simplesmente inatingíveis. E que, se não houvesse rápida renegociação do acordo, antes de sua posse, as pressões que ele teria de enfrentar nos primeiros momentos de governo seriam desastrosas, também. Por fim, agregou que não temia o risco da impo- pularidade diante das medidas amargas que teria de adotar, logo de saída. Fica a indagação: com Tancredo, chegaria o Brasil a decretar a moratória (suspensão temporária do pagamento da dívida), como se daria no governo Sarney?

A viagem ainda incluiu encontros com dirigentes do México, do Peru e da Argentina, sendo essa uma etapa com particularidades a sublinhar. O autor destaca o clima caloroso que se estabeleceu entre o presidente argentino Raúl Alfonsín e Tancredo, que puderam comentar, face a face, os respectivos processos de redemocratização em seus países. Bem como as instabilidades da América Latina: temia-se uma exacerbação da esquerda chilena, comprometendo o ainda débil equilíbrio formado por democratas cristãos e socialistas, a Bolívia vivia um momento de quase desintegração institucional, as ações do Sendero Luminoso no Peru davam fôlego aos radicais, os sandinistas na Nicarágua perdiam apoio interno e externo. Fora isso, Brasil e Argentina viviam as agruras da inflação, a estagnação econômica, o quadro geral de recessão. Esse primeiro diálogo presidencial pode bem ser visto como preâmbulo de um estreitamento de relações que levaria à constituição, mais tarde, do próprio Mercosul. Basta lembrar que, ainda em 1985, Alfonsín e Sarney assinariam a Declaração de Iguaçu, em que se estabelece a "associação preferencial" entre os dois países. Bom tempero para essa etapa da viagem é o relato de conversas do autor com o escritor argentino Jorge Luis Borges, convidado para um almoço em torno de Tancredo na embaixada do Brasil em Buenos Aires. Anotou Ricupero:

Borges está quase completamente cego e é acompanhado por uma jo- 


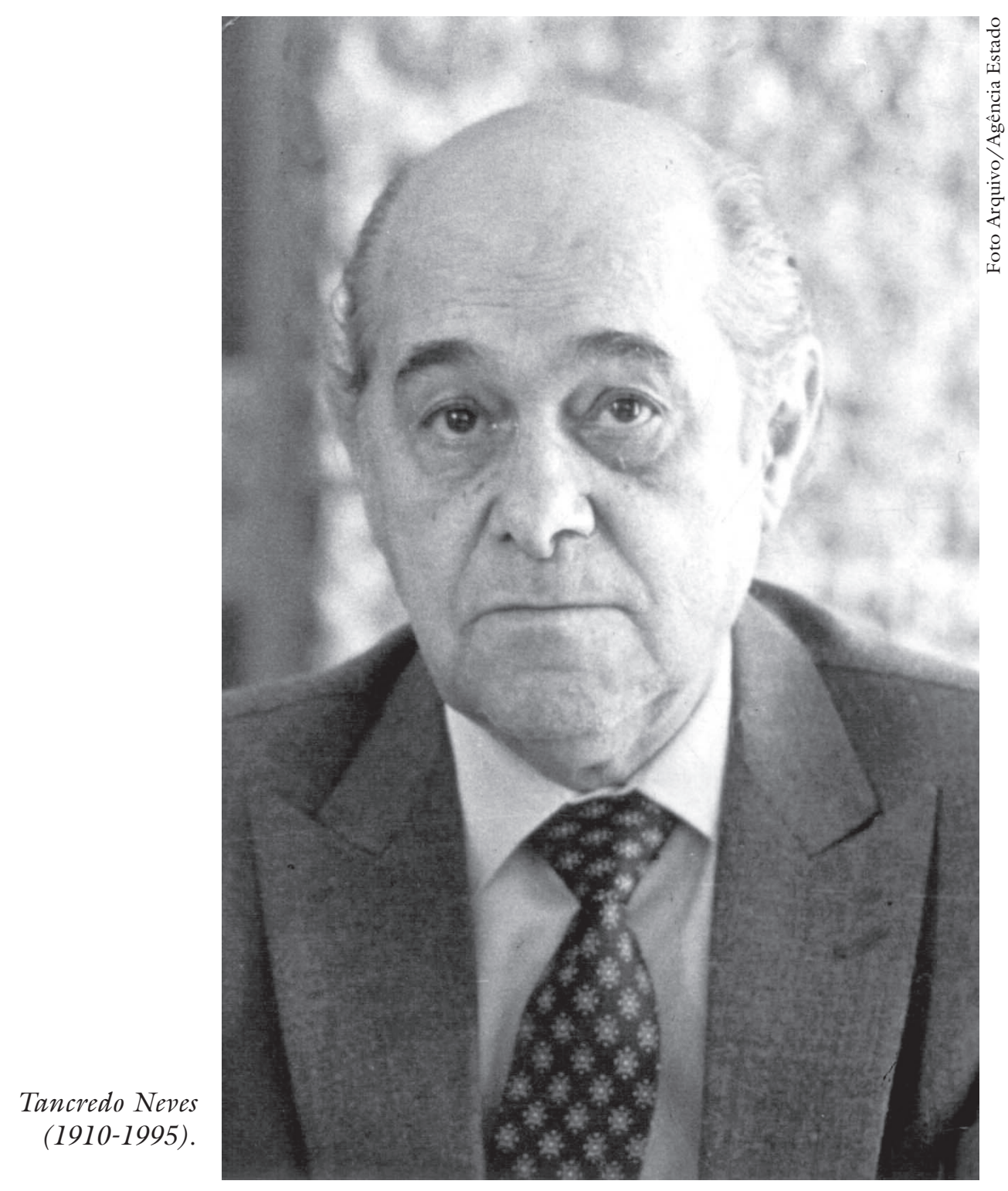

vem secretária de nome asiático [...]. Com 84 anos, parece relativamente bem, come com certo apetite embora evite carne e alguns tipos de alimentos. Adota às vezes um tom cínico e provocativo.

A jovem secretária é Maria Kodama, com quem o escritor se casou pouco tempo depois e que se tornaria a implacável guardiã da obra borgiana.

Diário de bordo inclui ainda o registro de conferências de imprensa de Tancre- do Neves ao longo da excursão, o que também ajuda a comprovar a tese de Rubens Ricupero: naqueles dias, era visível a crescente desenvoltura que Tancredo ganhou entre um encontro e outro, entre um briefing e outro de sua assessoria, entre uma entrevista e outra aos jornalistas. O presidente eleito foi exposto a diferentes vitrinas, estampou capas de revista no Brasil e fora dele, foi abraçado por poderosos e gente do povo. Era o símbolo vitorioso da Nova República, que 
em 2010 completa 25 anos, "esse quarto de século ininterrupto de democracia de massas", como define o ex-governador e hoje candidato à presidência José Serra, ao fim do livro: "Nesse quarto de século a alternância passou a fazer parte dos avanços adquiridos. Já ninguém mais contesta a legitimidade das vitórias eleitorais, do processo democrático e do natural desejo dos adversários vitoriosos de governar sem perturbações". O momento presidencial de Tancredo Neves foi efêmero em termos cronológicos. Mas de longo alcance em sua significação. Aécio Neves, neto e secretário particular do presidente eleito, acompanhou e viu tudo de perto naquele périplo alucinante. É herdeiro, mas não o único, do legado de uma brevidade que se perpetua no tempo histórico.

Laura Greenhalgh é jornalista, editoraexecutiva do jornal $O$ Estado de S. Paulo, responsável pelos cadernos culturais.

@ - laura.greenhalgh@grupoestado.com.br 